\title{
Cost-effectiveness of providing patients with information on managing mild low- back symptoms in an occupational health setting
}

J. Rantonen ${ }^{1,7,8,9^{*}}$, J. Karppinen ${ }^{1,4}$, A. Vehtari ${ }^{2}$, S. Luoto ${ }^{3}$, E. Viikari-Juntura ${ }^{1}$, M. Hupli ${ }^{3}$, A. Malmivaara ${ }^{5}$ and S. Taimela $a^{6,7}$

\begin{abstract}
Background: Evidence shows that low back specific patient information is effective in sub-acute low back pain (LBP), but effectiveness and cost-effectiveness (CE) of information in early phase symptoms is not clear. We assessed effectiveness and CE of patient information in mild LBP in the occupational health $(\mathrm{OH})$ setting in a quasi-experimental study.

Methods: A cohort of employees ( $N=312$, aged $<57$ ) with non-specific, mild LBP (Visual Analogue Scale between 10-34 mm) was selected from the respondents of an employee survey $(N=2480$; response rate $71 \%)$. A random sample, representing the natural course of $\operatorname{LBP}(N C, N=83$; no intervention), was extracted as a control group. Remaining employees were invited (181 included, 47 declined, one excluded) into a randomised controlled study with two 1:1 allocated parallel intervention arms ("Booklet", $N=92 ;$ "Combined", $N=89$ ). All participants received the "Back Book" patient information booklet and the Combined also an individual verbal review of the booklet. Physical impairment (PHI), LBP, health care (HC) utilisation, and all-cause sickness absence $(\mathrm{SA})$ were assessed at two years. CE of the interventions on SA days was analysed by using direct HC costs in one year, two years from baseline. Multiple imputation was used for missing values.

Results: Compared to NC, the Booklet reduced HC costs by $196 €$ and SA by 3.5 days per year. In $81 \%$ of the bootstrapped cases the Booklet was both cost saving and effective on SA. Compared to NC, in the Combined arm, the figures were $107 €, 0.4$ days, and $54 \%$, respectively. PHI decreased in both interventions.

Conclusions: Booklet information alone was cost-effective in comparison to natural course of mild LBP. Combined information reduced $\mathrm{HC}$ costs. Both interventions reduced physical impairment. Mere booklet information is beneficial for employees who report mild LBP in the $\mathrm{OH}$ setting, and is also cost saving for the health care system.
\end{abstract}

Trial registration: ClinicalTrials.gov NCT00908102

Keywords: Low back pain, The Back Book, Prevention, Quasi-experimental study, Sickness absence, Intervention, Disability, Cohort study, RCT, Health economy

\footnotetext{
* Correspondence: jarmo.rantonen@fimnet.fi

${ }^{1}$ Finnish Institute of Occupational Health (FIOH), P.B. 4000251 Helsinki,

Finland

${ }^{7}$ Hjelt Institute, Department of Public Health, University of Helsinki, Helsinki,

Finland

Full list of author information is available at the end of the article
} 


\section{Background}

Low back pain (LBP) is a common health problem that often leads to primary health care attention [1]. In the global scale, LBP is still the leading cause of disability and sickness absence among the workforce, yet inducing a huge impact on the economy [1-3]. Obviously, there is a need for innovative, cost-effective methods for managing LBP and for preventing the associated disability $[4,5]$.

Patient information can help patients understand and cope with their medical conditions and it may provide reassurance as regards their prognosis [6-10]. In order to promote efficient self-care, the content should be evidence-based or at least concurrent with existing guidelines [6, 11-13]. The optimal patient group and the type of information (personal or group, oral or written etc.) should also be determined. Moreover, it should be decided who is the main responsible person for the delivery of the information [14]. Educational booklets have been used in mediating general patient information, either alone or combined with, for example, personal verbal advice or educational group sessions [14]. The Back Book is probably the most widely used guideline-based patient information booklet for LBP [8, 13, 15-18].

In 2012, approximately 1.85 million Finnish employees (86\% of the total workforce) were covered by occupational health $(\mathrm{OH})$ service. Besides 1.1 million health examinations, $\mathrm{OH}$ also performed 5.2 million illness-related visits [19]. Because most employees use $\mathrm{OH}$ service for all their primary health care $(\mathrm{HC})$ needs, Finnish $\mathrm{OH}$ professionals are continually facing the challenge of how to manage employees' LBP-related disability [20-22].

Recently, we adopted the Back Book (booklet) based patient information for the self-management of mild (low-risk) LBP patients. The booklet alone was as effective in LBP-specific outcomes and sickness absence (SA) as the combination of the booklet and face-to-face verbal information in a randomized trial [15]. However, the feasibility of patient information was not fully assured since there was no comparison to the natural course of LBP in the previous trial.

In the present study we have assessed the clinical effectiveness and cost-effectiveness (CE) of providing booklet based patient information in comparison to the natural course of LBP (no intervention) on mild LBP in a longitudinal, quasi-experimental intervention trial in the $\mathrm{OH}$ setting. Direct health care $(\mathrm{HC})$ costs were compared to all-cause $\mathrm{SA}$ in the $\mathrm{CE}$ analysis.

\section{Methods}

\section{Study design and ethics}

The original study design was a longitudinal cohort study with two embedded RCTs and a control group that underwent no intervention (natural course of LBP). The detailed study design and results of both RCTs have been published elsewhere $[15,23]$.

All employees $(N=2480)$ in a forestry company were invited to respond to a postal survey on LBP and related PHI during September 2001. On the basis of their responses $(N=1754$, response rate $71 \%)$, employees were allocated into three main categories: "no" low back (LB) symptoms, "some" LB symptoms i.e. mild LBP (RCT1), and LB symptoms that "potentially hamper work" i.e. moderate LBP (RCT2). The main results of both RCTs have already been published. RCT2 showed that two multidisciplinary and active interventions reduced LBP, sickness absence and physical impairment among employees who were fit to work but reported moderate level LBP [23]. RCT1 showed that among employees who reported mild LBP (but were still able to work), booklet based patient information was as effective (in terms of clinical effectiveness) as additional face-to-face verbal advice with the booklet [15].

In this paper, we will focus on employees that reported some LBP symptoms, defined as mild LBP [24]. Alongside our previous RCT1 [15], we analysed the clinical effectiveness and cost-effectiveness of two patient information strategies in comparison with the natural course of LBP (no intervention), two years after the employee survey. Figure 1 shows the flow chart of the study participants at different stages of the intervention trial.

Throughout the study, information about the study procedures and the management of LBP were shared in collaboration with all stakeholders of the company (e.g. employer, employees, study personnel, trade union representatives and workers' compensation board).

The South Karelian Central Hospital Research Ethics Board approved the study, which was performed according to the Declaration of Helsinki.

\section{Study population}

Employees were eligible for the study, if they reported (in their responses to the postal questionnaire) LBP intensity between 10 and $34 \mathrm{~mm}$ on a $100-\mathrm{mm}$ Visual Analogue Scale (VAS) during the past week, were aged under 57, and fulfilled at least one of the following criteria:

1. LBP lasting two weeks or more in the previous 12 months

2. LBP radiating below knee level at the time of responding to the questionnaire

3. Recurrent LBP (two or more episodes during the previous 12 months, irrespective of their duration)

4. Self-reported work absence due to LBP during the previous 12 months

Exclusion criteria were: retirement within the time span of the follow-up, pregnancy, presence of acute nerve root 


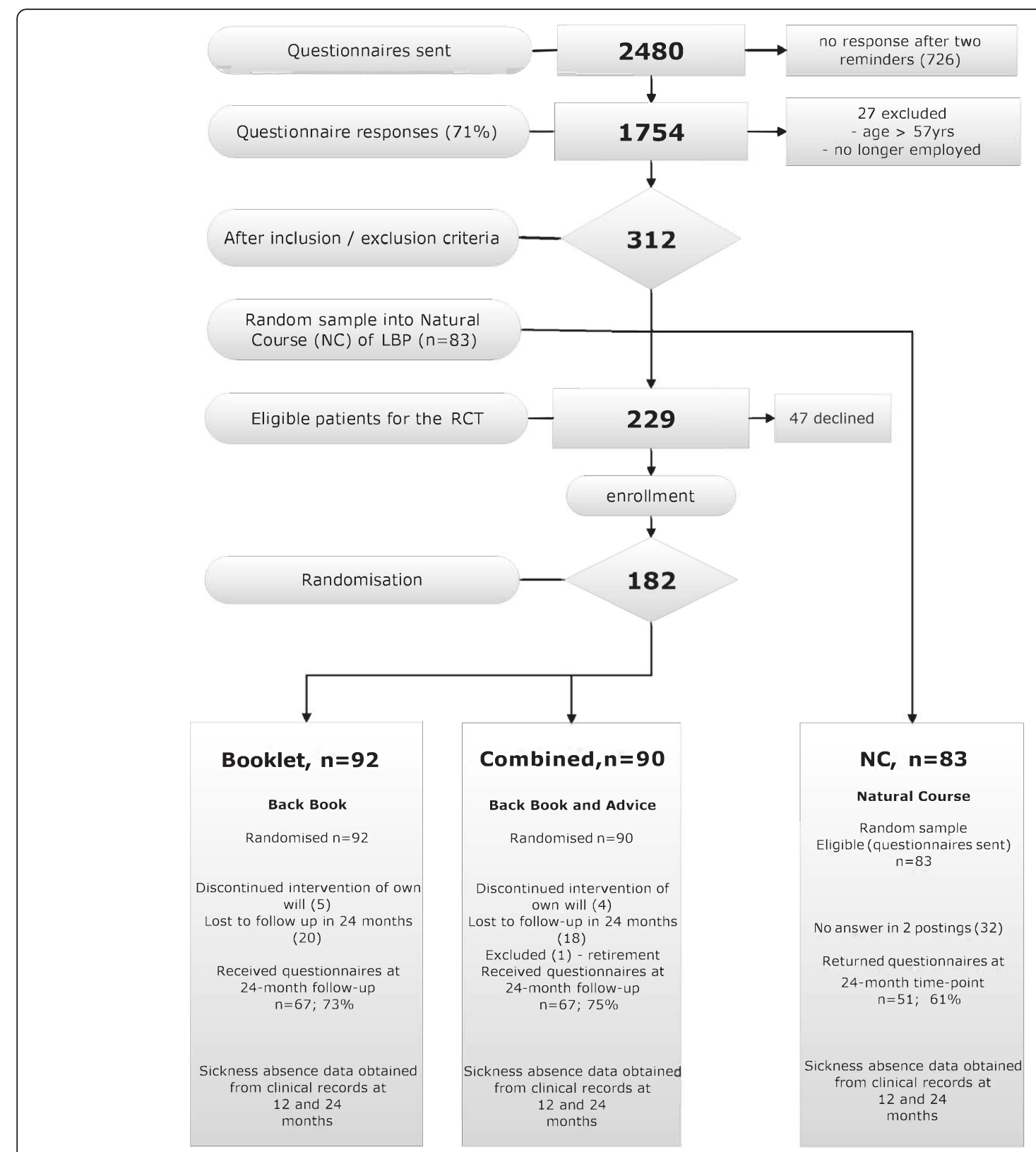

Fig. 1 Flow diagram of the course of the study, showing the number of participants at different phases of the trial [RCT, randomized controlled trial]

compression symptoms, suspicion of malignant tumours, recent spine fracture, severe osteoporosis or any other disease that prevented participation in the follow-up.

Sickness absence at the inclusion phase of the study was neither an inclusion nor an exclusion criterion for the study. Initially, employees were able to work regardless of their previous or present symptoms (whether LB related or other).

Eligible employees $(n=312)$ were defined as a mild LBP cohort. Since there is no gold standard for distinguishing mild LBP from moderate symptoms, the pain limits were chosen arbitrarily. Pain categorisation follows, for example, the recommendations of Boonstra et al. [24], who has categorised mild pain as VAS $\leq 34 \mathrm{~mm}$, moderate pain as between 35 and $74 \mathrm{~mm}$, and severe pain as $\geq 75 \mathrm{~mm}$.

Prior to the invitation to participate in the intervention, a random sample of employees (83) was extracted from the cohort in order to form a natural course (NC) control group. The remaining employees $(n=229)$ were invited to visit an $\mathrm{OH}$ nurse, who was specially trained in LBP problems and the main study procedures. A total of $182 \mathrm{em}$ ployees were randomised (47 declined to participate) into two intervention arms, Booklet (Back Book) and Combined (Back Book and Advice), but soon after randomisation, one 
person was excluded from the Combined group due to retirement. Therefore, finally 181 participants (Booklet, $n=92$ and Combined, $n=89$ ) were included in the intervention groups. Of the 83 employees that were eligible for $\mathrm{NC}, 51$ responded to the postal questionnaire, resulting in missing data for 32 employees.

Table 1 shows the distribution of some basic characteristics (employee survey data) in the study groups. Throughout the study, all participants were able to use $\mathrm{HC}$ services as usual, either at $\mathrm{OH}$ services or other available $\mathrm{HC}$ units.

\section{Randomisation and blinding}

The NC group was extracted from the mild LBP cohort as a random sample by means of a computer program. Remaining employees were invited to the first study visit.

The randomisation scheme for the trial was prepared by an independent biostatistician before the study was started by using a computer-generated randomisation table with a block size of eight. A research assistant prepared the sealed envelopes that included the group assignments, referral either to the Booklet or the Combined group.
During the first study visit, $\mathrm{OH}$ nurse informed the employee about the study, collected the informed consent, performed a clinical examination and explained the findings to the employee. After that, she opened the sealed envelope that included the assignment for either of the two interventions, according to the randomisation scheme. More details of the original RCT are explained elsewhere [15]. In order to ensure blinded analysis, all study data were entered into the data file by persons who were not related to the study.

\section{Interventions}

The company $\mathrm{OH}$ services unit operated as usual during the study period, and information about the study was provided regularly in the personnel magazine of the company and intranet.

At the end of the first study visit, the $\mathrm{OH}$ nurse gave the Back Book (booklet) to all participants and presented additional face-to-face oral review of the booklet into those participants who were randomised into the Combined arm.

Table 1 Basic characteristics of the study participants

\begin{tabular}{|c|c|c|c|c|c|c|c|c|c|c|}
\hline \multirow[t]{2}{*}{ Characteristics } & \multicolumn{3}{|c|}{ Combined $(n=89)$} & \multicolumn{3}{|c|}{ Booklet $(n=92)$} & \multicolumn{3}{|c|}{$\mathrm{NC}(n=83)$} & \multirow[t]{2}{*}{$p$} \\
\hline & $\%$ & mean & SD & $\%$ & mean & $\mathrm{SD}$ & $\%$ & mean & $\overline{S D}$ & \\
\hline \multicolumn{11}{|l|}{ Demographics } \\
\hline Age (years) & . & 44 & 8 & . & 43 & 7 & . & 45 & 8 & 0.52 \\
\hline Male & 79 & . & . & 66 & . & . & 76 & . & . & 0.55 \\
\hline Smoking & 30 & . & . & 28 & . & . & 31 & . & . & 0.35 \\
\hline High school diploma/vocational degree & 79 & . & . & 75 & . & . & 76 & . & . & 0.87 \\
\hline \multicolumn{11}{|l|}{ General health } \\
\hline Duration of LBP, years & . & 12 & 9 & . & 11 & 7 & . & 14 & 9 & 0.09 \\
\hline SA days before baseline ${ }^{a}$ & & & & & 9 & 12 & & 14 & 19 & 0.10 \\
\hline \multicolumn{11}{|l|}{ Work-related features } \\
\hline Blue collar worker & 69 & . & . & 64 & . & . & 78 & . & . & 0.05 \\
\hline Shift worker (two or three shift work) & 41 & . & . & 37 & . & . & 40 & . & . & 0.73 \\
\hline Physical workload $(1-5)^{b}$ & . & 3 & 1 & . & 3 & 1 & . & 3 & 1 & 0.13 \\
\hline Mental workload $(1-5)^{\mathrm{b}}$ & . & 3 & 1 & . & 3 & 1 & . & 3 & 1 & 0.51 \\
\hline Work ability $(0-10)^{c}$ & . & 8.1 & 1.5 & . & 8.3 & 1.5 & . & 7.8 & 1.6 & 0.07 \\
\hline \multicolumn{11}{|l|}{ Outcome variables at baseline } \\
\hline Physical impairment (PHI); RM-18 (0-18) ${ }^{\mathrm{d}, \mathrm{e}}$ & . & 4.2 & 4.6 & . & 2.5 & 3.2 & . & 3.9 & 3.6 & 0.34 \\
\hline Low back pain (LBP); VAS $(0-100)^{\mathrm{d}}, \mathrm{mm}$ & . & 20 & 7 & . & 20 & 7 & . & 19 & 7 & 0.52 \\
\hline \multicolumn{11}{|l|}{ Other LB specific variables } \\
\hline Fear Avoidance Beliefs Questionnaire $(13-78)^{d}$ & . & 29 & 10 & . & 29 & 11 & . & 31 & 11 & 0.15 \\
\hline
\end{tabular}

all cause sickness absence days during 12 months prior to baseline (register data)

b $1-5$ indicates self-rated load: $1=$ very heavy, $2=$ moderate, $3=$ intermediate, $4=$ rather light, $5=$ very light

' range $0-10$, when 0 is lowest possible work ability and 10 is best possible work ability

${ }^{d}$ Higher value indicates higher impairment, pain or fear of pain, respectively

${ }^{e}$ for the comparison between Booklet and $\mathrm{NC}$, mean difference of $\mathrm{PHI}$ is significant $(p=0.01)$

Means ( $\mathrm{SD}=$ standard deviation) or percentages when applicable. Intervention groups were pooled for the comparison between the intervention and NC. [Combined = Back Book and Advice intervention group; Booklet = Back Book intervention group; NC Natural Course control group; BMI Body mass Index; SA sickness absence; $L B P$ low back pain; VAS Visual Analogue Scale; $R M$-18 Roland-Morris 18-item Disability Questionnaire; $P H I$ Physical impairment; $p=P$-value]. Missing values (concerning smoking, duration of LBP and shift work) were imputed with the multiple imputation procedure 
The randomisation visit lasted about $60 \mathrm{~min}$ in the Booklet group, whereas in the Combined group, the additional review of the booklet, face-to-face with the employee required 20 min more.

Follow-up visit intervals were similar in both intervention groups, scheduled at 3, 6, 12, and 24 months from the first visit. During scheduled visits, $\mathrm{OH}$ nurse checked the returned questionnaire responses, performed a simple clinical balance test, and answered questions that may have arisen among the participants. Generally, the follow-up questionnaires had been filled in by the employees during the week prior to the visit date. Both intervention groups were comparable as regards the follow-up intervals, visit activity and the time spent (30 $\mathrm{min})$ at the follow-up visits.

NC group received a postal questionnaire, similar to those addressed to the intervention groups and scheduled at 24 months from the start of the whole study. For this paper, we have analysed the 24-month questionnaire data, because it is comparable between the intervention groups and $\mathrm{NC}$.

\section{Booklet $(n=92)$}

Participants received a personal copy of the booklet. They underwent no other intervention.

The information in the booklet is based on the biopsychosocial model and focuses on attitudes and inappropriate behaviour concerning LBP. The booklet has been designed to complement and support evidence-based LBP management strategies, and its key messages follow the current national guidelines. It also includes information on how to cope with LBP, avoid re-exacerbation of LBP, and emphasises that one should reassume normal activities and return to work as soon as possible. The book has been translated into Finnish from the original English version [8].

\section{Combined $(n=89)$}

Participants in the Combined group received the booklet during their first visit, but the contents of the booklet were also reviewed to them face-to-face by the $\mathrm{OH}$ nurse.

\section{$N C(n=51)$}

Participants in the NC group were not invited to study visits, but the study questionnaire was sent to them 24 months after the employee survey. Non-respondents of the first postal questionnaire were sent one reminder soon after the first one. Of the 83 eligible employees, 51 (61\%) responded to the questionnaire and were included in the complete case analysis.

\section{Use of health care $(\mathrm{HC})$ resources}

About 24 months after the employee survey (i.e. baseline), participants in all study groups were asked to report their
$\mathrm{HC}$ utilisation during the previous 12 months, i.e. 1324 months after the baseline. The questionnaire included the following items: the number of visits to a physician, nurse, physiotherapist or other $\mathrm{HC}$ professional; each representing a unit of $\mathrm{HC}$ utilisation. These items were included in the following $\mathrm{HC}$ categories: $\mathrm{OH}$, public (primary) $\mathrm{HC}$, private $\mathrm{HC}$, hospital outpatient clinics, and hospital inpatient care and rehabilitation clinics. The number of radiological procedures during the previous 12 months and the visits that relate to alternative or complimentary $\mathrm{HC}$ (acupuncture, massage, chiropractor etc.) were also included. Our $\mathrm{HC}$ usage data shows separately the visits in the $\mathrm{OH}$, public $\mathrm{HC}$ and private sector, but they all may be considered as primary care visits. Service-wise the contents of care are comparable. Because their unit costs vary, we have presented them separately. The unit costs were obtained from the national working paper of the Finnish Ministry of Social Affairs and Health [25], expressed in euros, and converted to the 2004 level (the final follow-up visit was in 2004). Additional table shows the use of $\mathrm{HC}$ resources over 12 months, scheduled at 13-24 months from the baseline (see Additional file 1).

We have focused on the direct $\mathrm{HC}$ costs and considered SA as the primary outcome of the CE analysis. Travelling costs and productivity losses (i.e. employee not working in his/her working time) were not included in the costs. All study participants were working at the same industrial complex area. Intervention cost was evaluated with the extra time consumed for the verbal patient information in the $\mathrm{OH}$ nurse visit (20€/person). In proportion to the 12-month $\mathrm{HC}$ costs, we also collected all cause SA days from 12 months into our cost-effectiveness analysis (CEA). Cost-effectiveness (CE) was evaluated from the health care perspective and the $\mathrm{HC}$ usage as well as the SA data in CEA covered the same time period (12 months, timeline of 13-24 months from baseline).

\section{Health outcomes}

Baseline measurements originate from the employee survey. The follow-up measurements were performed 24 months after the baseline. Time interval is the same in all study groups. Clinical effectiveness was evaluated with the following variables: physical impairment (PHI), intensity of LBP and accumulated, all cause sickness absence (SA). PHI was measured with the Roland-Morris Disability Questionnaire 18-item scale [26, 27], and LBP by the Visual Analogue Scale (VAS; 0-100 mm) [28]. SA data were gathered at one-year intervals up to two years after the individual randomisation date of the participants in the intervention groups. As regards the NC group, SA count started from the postal date of the employee survey. SA data is comprehensive and highly reliable because it is based on the administrative payroll 
system of the employer. There were no missing values in the SA data, either. Since all SA episodes in the $\mathrm{OH}$ service's administrative registration system included ICD-10 [29] classification numbers, we were able to distinguish LB specific SA from the other cause SA episodes. Although the total (=all cause) SA days were included in the final analyses, each SA episode that was not LB-specific and at the same time longer than 30 days was omitted from the analysis in order to prevent severe diseases (other than LB specific) and sequels of injuries (other than LB specific) from interfering with the analysis. Therefore, SA data includes all LB specific SA episodes, regardless of their length, and all other cause SA episodes that are less than 31 days. The cut-off limit of 30 days per SA period was chosen arbitrarily.

\section{Power calculations}

In the two-arm randomised trial the power calculations were based on the following assumptions: the estimated standard deviation for the PHI score in our population was 4 units. A difference of 2 units between treatment arms is detectable with $85 \%$ power in two-tailed tests with the alpha of 0.05 for a sample of 73 employees in each group, and the standardised effect size is 0.50 .

\section{Statistical analyses}

All statistical analyses were performed at employee level, according to the intention-to-treat principle. About $29 \%$ of the data concerning $\mathrm{HC}$ costs and health outcomes were missing, mostly due to missed follow-up visits. However, all participants in this study had an equal opportunity to attend the follow-up visits or send their questionnaire information to the study personnel. Therefore, we have assumed that the missing data is missing at random. All missing data were imputed with the multiple imputation method [30] by using the SPSS Statistical Package version 22.0 for Windows ${ }^{\bullet}$ (SPSS Inc., Chicago, IL, USA).

The following items were either used as determinants or were also imputed (if used with outcomes or characteristics) in the multiple imputation procedure: age, gender, marital status, education, smoking, lifetime duration of LBP, self-assessed health status, working status, shift work, physical workload, mental workload, self-assessed work ability, job satisfaction, physical impairment, LBP, pain related fear, all cause SA 12 months prior to employee survey, all cause SA in the first follow-up year.

We have presented our results from the basis of two databases, the complete case (original) data and the imputed data (main analysis). Basic characteristics were compared using descriptive statistics. Intervention groups were pooled for the comparison.

The effectiveness of an intervention was primarily estimated by the group difference (Combined vs. NC; Booklet vs. NC) of the outcome variable (PHI and LBP) after two years. For the clinical effectiveness analysis, SA days were accumulated in two years from the baseline. Statistical analyses of the clinical outcomes were performed with the SPSS 22.0 for Windows.

For the cost-effectiveness analyses, SA data were gathered in 13-24 months from the baseline in order to comply with the timeframe of $\mathrm{HC}$ costs in an equal way in all study groups. Typically, SA distributions were skewed.

Some of the total $\mathrm{HC}$ usage data required manual corrections before transmission into the computer database. For instance, the costs of some radiological tests were accounted manually because of variable unit costs of the different tests.

In order to assess the uncertainty in CEA, we performed a one-way sensitivity analysis and a probabilistic sensitivity analyses (Monte Carlo method and Bayesian, non-parametric bootstrapping with 10000 replicates) of the comparisons between the intervention groups and NC.

Incremental cost-effectiveness ratio (ICER) is the cost-difference of two interventions divided with the difference of their effects. Hence, ICER summarizes the cost-effectiveness of an $\mathrm{HC}$ intervention by representing the average incremental cost $(€)$ which associates in one additional unit of effect (SA day).

One way sensitivity analysis shows how the change in one unit cost influences in the ICER ( $€$ per sickness absence day), when other values remain at their base level.

The results of the CEA main analysis are presented as CE-planes, mean incremental costs (IC) and effects (IE) with corresponding $95 \%$ confidence intervals $(95 \% \mathrm{CI})$ and the ICER. The uncertainty of CE planes was evaluated with cost-effectiveness acceptability curves (CEAC), which are presented in the additional files. One-way sensitivity analyses for the ICERs are presented in tornado diagrams. The results of the imputed main analysis have also been compared to the complete case analysis (original data).

\section{Lost to follow-up}

Within the first three months, four participants from the Combined and five from the Booklet group left the study due to personal reasons, but granted permission to use their data. At the end of the two-year follow-up, 18 participants from the Combined, and 20 participants from the Booklet failed to return their questionnaires, resulting in missing data. The reasons for not continuing with the study remained mostly unknown to the researchers. In both intervention groups, 67 participants continued to the end of the two-year follow-up (activity rates: Combined $73 \%$ and Booklet $75 \%$ ). In the NC group, 32 of the eligible 83 persons did not return the postal questionnaire, meaning that the complete data is available for 51 (61\%) participants. 
Complete case analysis includes only those participants who returned their $\mathrm{HC}$ utilisation questionnaires in the 24-month visit. In the main analysis, however, SA data (as also the multiply imputed questionnaire data) were analysed among all study participants.

\section{Results and discussion Use of $\mathrm{HC}$ resources}

According to the reported $\mathrm{HC}$ usage (see Additional file 1), the direct $\mathrm{HC}$ cost per person in the Combined $(n=67)$, Booklet $(n=67)$ and NC $(n=51)$ groups was $188 €$ (range: 0 - 6543€; quartiles: 20, 20, 77€), 73€ (range: 0-773€; quartiles: $0,0,65 €$ ) and $370 €$ (range: $0-3379 €$; quartiles: 0 , $0,387 €)$, respectively. The corresponding sums for the three groups were $12580 €, 4880 €$ and $18863 €$ per year.

\section{Cost effectiveness (main) analysis (CEA)}

Using the imputed cost data (main analysis) of 264 participants, the Booklet intervention was less costly and more effective than $\mathrm{NC}$ in a timeframe of 13-24 months after baseline. Also the Combined intervention reduced $\mathrm{HC}$ costs, but the effectiveness was only modest. The ICER in Booklet vs. NC was $54 €$ and in Combined vs. NC $315 €$ meaning the amount of money required for each avoided SA day. The estimated mean monetary savings over a year were $190 €$ and $126 €$ per person, respectively (see Additional file 2).

\section{One-way sensitivity analyses}

Booklet vs. NC was not sensitive to any cost variable. The ICER varied from $-71 €$ to $-45 €$ per SA day avoided (Fig. 2a). In Combined vs. NC, however, the ICER varied from -530 to $15 €$ (Fig. 2b) meaning that the result was sensitive to a single expensive cost item (rehabilitation days).

\section{Probabilistic sensitivity analysis}

For Booklet vs. NC, the mean incremental cost (with $95 \% \mathrm{CI}$ ) was $-196 €(-308--96)$, (negative figure indicates savings) and the mean incremental effect -3.5 (95\% CI -10 - 3.8), representing avoided work absence. According to the CE plane (Fig. 3a), the base case and also $81 \%$ of the simulated cases were situated in the south-eastern (SE) quadrant, suggesting that the intervention was both cost saving and more effective (see Additional file 2). All bootstrapped, simulated cases were located below the horizontal line showing that the intervention clearly reduced $\mathrm{HC}$ costs.

According to CEAC, at any level of willingness to pay for a SA day avoided the probability of the Booklet intervention being acceptable is $81 \%$ (for any positive cost of a SA day) (see Additional file 3).

For Combined vs. NC, the mean incremental cost (with $95 \% \mathrm{CI}$ ) was $-107 €(-258-61)$, (negative figure indicating savings), but the mean incremental effect was only marginal, -0.4 days $(-7.5-7.8)$, representing avoided work absence. Although the base case was located in the SE quadrant suggesting more effectiveness and fewer costs, only about $54 \%$ of the simulated, bootstrapped cases (Fig. 3b) fell in that quadrant (see also Additional file 2). However, about $87 \%$ of the simulated cases lay in the two southern quadrants indicating reduced $\mathrm{HC}$ costs.

According to the CEAC, at any level of willingness to pay for a SA day avoided the probability of the Combined intervention being acceptable is between $62 \%$ and $57 \%$ (from zero cost to all costs above 200€) (see Additional file 3).

\section{Sensitivity analysis using two data sets}

The results and the conclusions drawn from the complete case analysis were largely comparable with the main analysis (see Additional file 2). Few differences were noticed, however. The Combined intervention was more costeffective in the complete case analysis and the results were not that sensitive to one cost item as in the main analysis (data not shown).

\section{Sickness absence days}

All cause SA days during two years were trend-wise lower in both intervention groups in comparison to NC (Table 2).

\section{Other health outcomes}

According to the main analysis, the mean difference of PHI in Booklet vs. NC, two years from baseline, was -2.5 [95\% CI $-3.8--1.3$ ], and for Combined vs. NC -1.5 [95\% CI $-2.8--0.3]$. The LBP intensity tended to decrease in both arms, but the changes were not statistically significant (Table 2 ).

\section{Main findings}

Booklet information was cost-effective in comparison to the natural course of LBP. In short, a delivery of simple written information reduced the direct health care costs and saved sickness absence days. Although the combination of booklet information and face-toface advice also reduced the costs of health care (87 \% probability), the effectiveness of the intervention on sickness absence was negligible. The costeffectiveness analysis of the combined intervention was also sensitive to a single cost item. Physical impairment also decreased in both intervention groups over the two years.

\section{Strengths and weaknesses of the study}

The main strengths of the study lie in the pragmatic $\mathrm{OH}$ setting, the inclusion of the natural course control group, and the long-term follow-up. Comprehensive and reliable sickness absence data are also an asset in this 

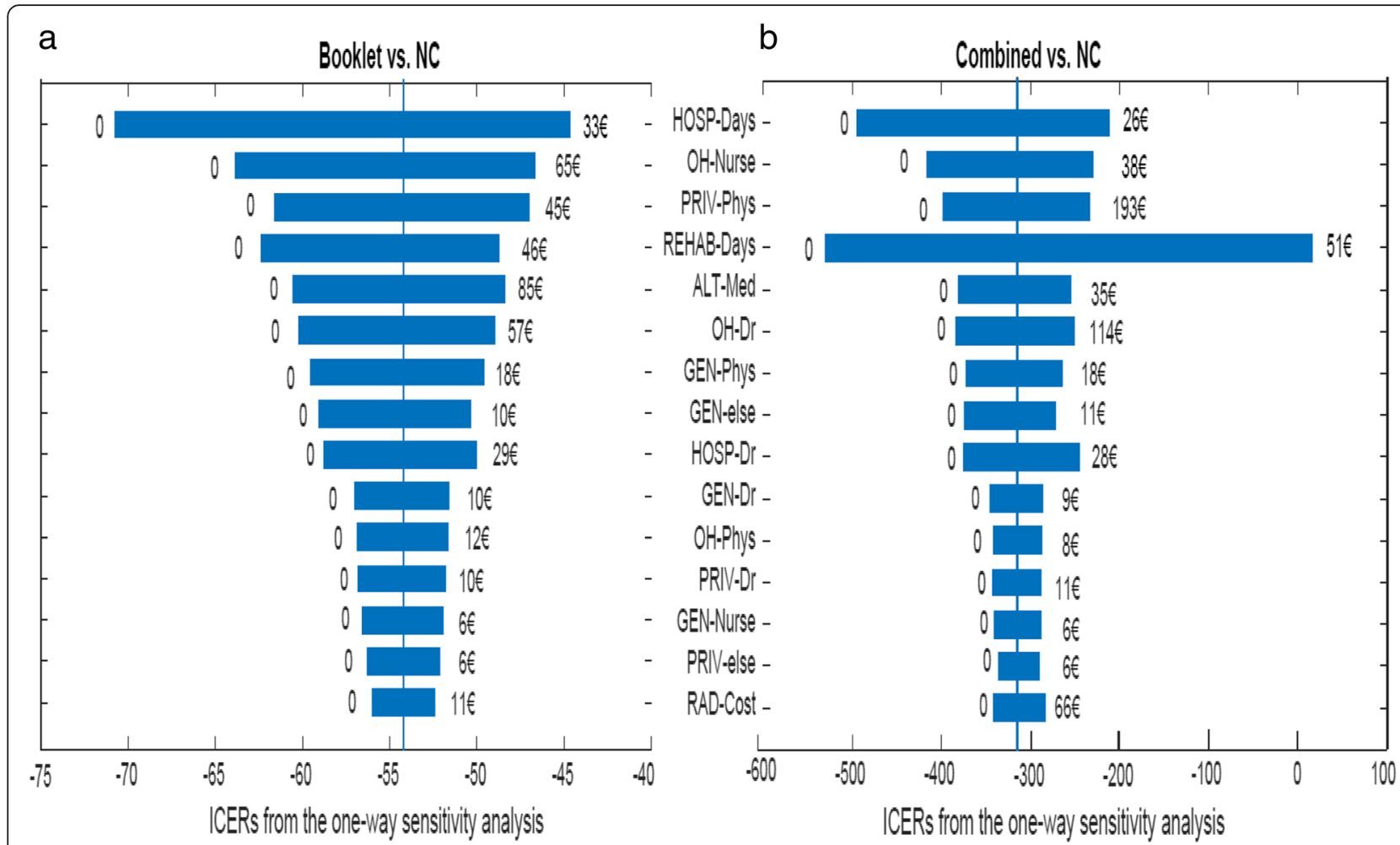

Fig. $\mathbf{2}$ a and $\mathbf{b}$ One-way sensitivity analyses (tornado diagrams) for the comparisons of Booklet vs. NC (a) and Combined vs. NC (b). Horizontals bar indicate the change in every cost variable ranging from percentiles 5 to $95 \%$. The graph shows the influence of the change in one unit cost in the ICER ( $€$ per sickness absence day), when other values remain at their base level. Around the ICER, bars may be asymmetric because of the Bayesian statistical procedure. In both graphs, variables were sorted according to their influence in the comparison of Booklet vs. NC (most influential variable on top). Variables OH-else, HOSP-Nurse, PRIV-Nurse, HOSP-Phys, HOSP-else and INTCOST have been deleted because of minimal effects in the ICER. The descriptions of all cost-items are shown in the Additional file 1 [Booklet, Back Book booklet group; Combined, Back Book with oral advice group; NC, natural course of LBP group]

study. This quasi-experimental cost-effectiveness study was prepared alongside with our previous RCT [15]. Employees were invited to participate in the study on the basis of a health risk appraisal (response rate $71 \%$ ) that comprised items of LBP, sciatica and LBP history. All employees who were included in the study groups shared the same eligibility criteria and were primarily not sick-listed. Natural course of LBP (NC) group acted as the control for the interventions. $\mathrm{NC}$ was a random sample from the same cohort as the intervention groups and received no intervention. Although the study is based on a single industrial location, the study cohort aptly represents the general distribution of the Finnish workforce (age, gender, socio-economic class).

Generally, sickness absence serves as a measure of health in the working population when health is understood as a mixture of social, psychological and physiological functioning [31, 32]. The sickness absence data in this study were highly reliable also because the same data were used as a basis for the health insurance payments in the company.
The health care usage in our study may look very different from other health care systems. However, all public, private and occupational health care visits in our data may be considered as components of a uniform primary $\mathrm{HC}$ resource use. Considering the pragmatic study design, a real life $\mathrm{OH}$ organisation and comprehensive SA data, our results can be easily transferred to $\mathrm{OH}$ practice and to some extent to primary care, as well.

Some weaknesses were identified, though. The quasiexperimental study design may be considered as such, although we were able to include the NC group as a comparison, which - on the other hand - is a definite strength. The study groups were comparable as regards the basic characteristics (Table 1). However, the proportion of blue collar workers was slightly higher in the NC group and they assessed their work ability lower (borderline difference) than those in the intervention groups (the intervention goups were pooled for the comparison). However, since there were no differences in physical and mental workload or in several LB-specific 

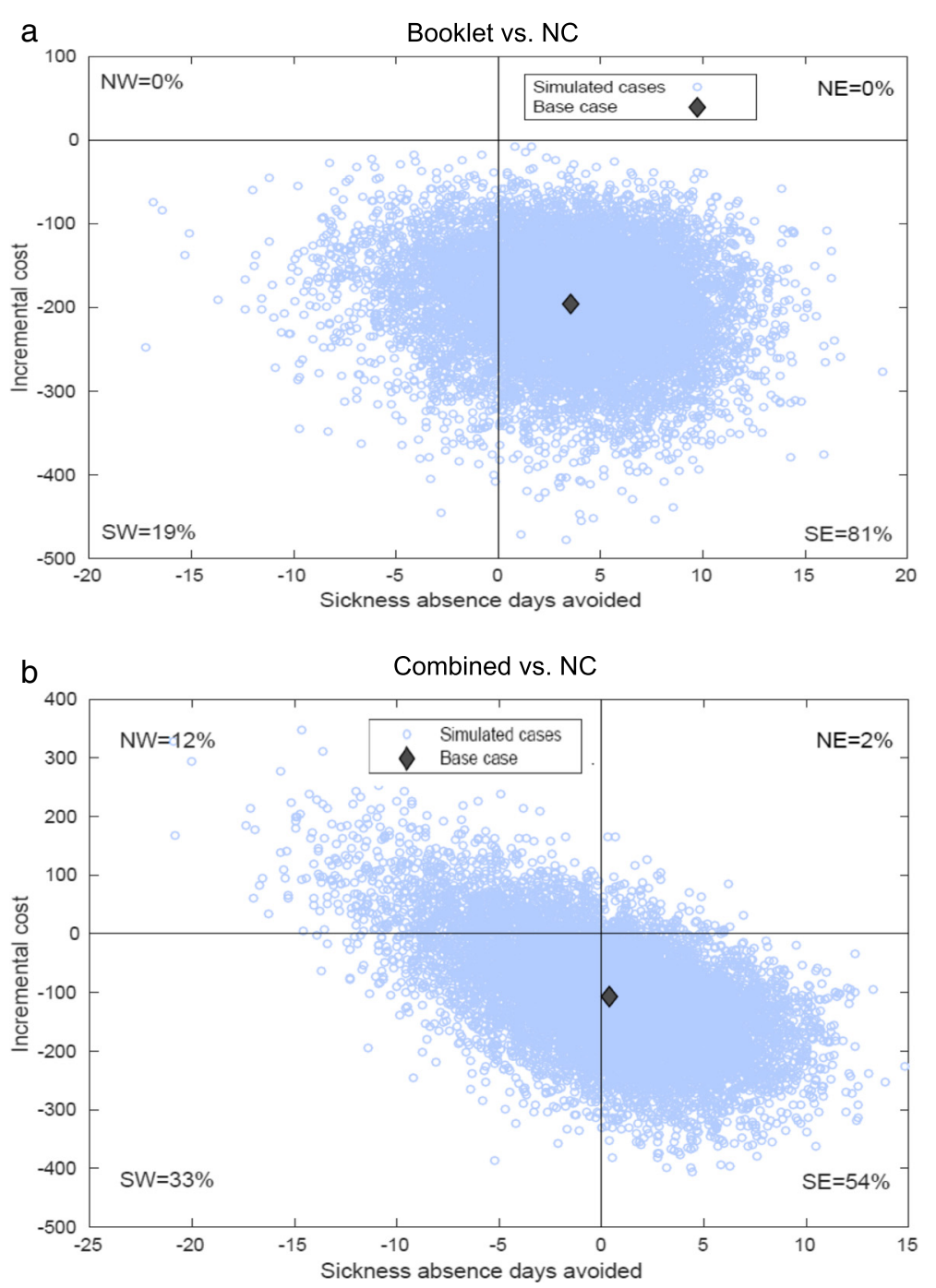

Fig. $\mathbf{3}$ a and $\mathbf{b}$ Cost-effectiveness (CE) planes for the comparisons of Booklet (a) and Combined (b) vs. NC. Base case is indicated with a diamond and bootstrapped, simulated cases with small dots. Both graphs show the probability of the bootstrapped, simulated cases across the CE plane quadrants. In the north-eastern (NE) quadrant, intervention group is considered more costly and more effective than the control group and in the north-western (NW) quadrant, more costly and less effective, in the south-western (SW) less costly and less effective and in the south-eastern (SE) more effective and less costly, respectively. [See also Additional file 2]

variables (PHI, intensity of LBP, pain-related fear) prior to the study, pre-study sickness absence or LB history, NC is considered comparable with the intervention groups.

In contrast to a fairly good follow-up participation in the intervention groups (73-74\%), the response rate in the NC group was somewhat lower (61\%), which could potentially indicate selective participation and cause bias. All study participants were familiar with the study questionnaires, having already responded to the employee survey at the beginning of the study. NC group members were also able to respond to their questionnaires like their fellow participants. Hence, we do not recognise any systematic reason or occurrence that would explain the missed follow-up visits.
We have analysed the $\mathrm{HC}$ utilisation data from the time-period of 13-24 months in this study, because the NC group received only one follow-up questionnaire, scheduled at 24-months after the study started. The same questionnaire was used with all participants and it covered $\mathrm{HC}$ utilisation from the last 12 months. This may be considered as weakness, but we opted not to intervene in the $\mathrm{NC}$ group by any means during the follow-up of two years. We also thought that the $\mathrm{HC}$ utilisation recall period could not be longer than 12 months. We were aiming for secondary prevention of symptoms and were expecting long-term results, longer than just 12 months. Recall bias is considered similar in all groups, due to the uniform data collection. 
Table 2 Results of the study outcome variables

\begin{tabular}{|c|c|c|c|c|c|c|c|c|c|c|c|c|c|c|}
\hline \multirow[t]{2}{*}{ Outcomes/analysis } & \multicolumn{2}{|c|}{ Combined } & \multicolumn{2}{|c|}{ Booklet } & \multicolumn{2}{|l|}{$\mathrm{NC}$} & \multicolumn{2}{|l|}{ Total } & \multicolumn{3}{|c|}{ Combined vs. NC } & \multicolumn{3}{|c|}{ Booklet vs. NC } \\
\hline & mean & SD & mean & $S D$ & mean & SD & mean & $S D$ & $\mathrm{MD}$ & $95 \% \mathrm{Cl}$ & $p$ & $\mathrm{MD}$ & $95 \% \mathrm{Cl}$ & $p$ \\
\hline \multicolumn{15}{|l|}{ Main analysis $^{a}$} \\
\hline $\mathrm{PHI}$ & 3.0 & 3.6 & 2.0 & 2.9 & 4.5 & 3.8 & 3.1 & 3.6 & -1.5 & $-2.8--0.3$ & 0.01 & -2.5 & $-3.8--1.3$ & 0.00 \\
\hline LBP & 21 & 22 & 20 & 20 & 23 & 19 & 21 & 20 & -2 & $-9-6$ & 0.86 & -3 & $-11-4$ & 0.51 \\
\hline SA first year & 12 & 22 & 12 & 18 & 16 & 30 & 13 & 24 & -5 & $-13-4$ & 0.39 & -4 & $-13-4$ & 0.56 \\
\hline SA second year & 16 & 38 & 12 & 34 & 16 & 23 & 15 & 32 & 0 & $-12-11$ & 1.00 & -4 & $-15-8$ & 0.74 \\
\hline SA total in two years & 27 & 50 & 24 & 48 & 32 & 43 & 28 & 47 & -5 & $-22-12$ & 0.76 & -8 & $-25-9$ & 0.50 \\
\hline $\mathrm{HC}$ costs in 12 months, $€$ & 195 & 700 & 108 & 142 & 303 & 577 & 199 & 530 & -108 & $-297-82$ & 0.37 & -195 & $-382--7$ & 0.04 \\
\hline \multicolumn{15}{|l|}{ Complete case analysis ${ }^{\mathrm{b}}$} \\
\hline $\mathrm{PHI}$ & 2.6 & 3.8 & 1.5 & 3.1 & 4.1 & 4.1 & 2.6 & 3.8 & -1.4 & $-3.0-0.1$ & 0.10 & -2.6 & $-4.2--0.9$ & 0.00 \\
\hline LBP & 20 & 23 & 17 & 22 & 23 & 22 & 20 & 22 & -2 & $-12-8$ & 0.87 & -5 & $-15-4$ & 0.41 \\
\hline SA first year & 13 & 25 & 12 & 19 & 13 & 20 & 13 & 22 & 0 & $-10-10$ & 1.00 & -2 & $-11-8$ & 0.93 \\
\hline SA second year & 16 & 42 & 13 & 39 & 17 & 23 & 15 & 37 & -1 & $-17-15$ & 0.99 & -4 & $-20-12$ & 0.84 \\
\hline SA two years & 29 & 55 & 25 & 54 & 30 & 32 & 28 & 49 & -1 & $-23-21$ & 0.99 & -5 & $-27-16$ & 0.83 \\
\hline $\mathrm{HC}$ costs in 12 months, $€$ & 188 & 808 & 73 & 151 & 370 & 730 & 196 & 633 & -182 & $-457-93$ & 0.26 & -297 & $-572--22$ & 0.03 \\
\hline
\end{tabular}

${ }^{a}$ Main analysis includes 264 participants in Combined (89), Booklet (92) and NC (83) groups

${ }^{b}$ Complete case analysis includes 185 participants in Combined (67), Booklet (67) and NC (51) groups

The main analysis includes multiply imputed data of 264 cases and complete case analysis includes the original, available data ( $n=185)$. Table shows the means and standard deviations in all study groups and the group comparisons between intervention groups (Combined and Booklet) and control (NC natural course group). [Mean, standard deviation (SD), mean difference (MD), $95 \%$ confidence interval (95\% Cl), p-value of the group comparison, $P H I$ Physical impairment by the Roland-Morris 18-item Disability Questionnaire (range 0-18), LBP low back pain in Visual Analogue Scale (VAS, range 0-100 mm), SA sickness absence (days), $H C$ health care]

Figures are bolded when considered statistically significant

Although study participants were advised to exclude their study visits from $\mathrm{HC}$ utilisation, in a few cases, some may have mistakenly included them. Because all study participants were working in the same company, the NC group may have been somewhat contaminated by the interventions. However, contamination or inclusion of study visits would more likely have diluted the differences between the intervention and control groups than increased them.

At first it seems surprising that the cost-effectiveness of combined patient information was weaker than the booklet information alone. Some characteristics about the verbal information might explain at least part of this controversy. According to Henrotin et al, patient information should be consistent even though it is delivered to patients in various methods [33] like verbal, written, video etc. Otherwise, distracted information may cause confusion among the patients and diminish the effect of the information. Verbal advice is very sensitive to inconsistency or disturbances per se. Physical and social environment of the patient and nurse, nurse-patient interaction, or intrapersonal characteristics can disturb the fragile connection between the patient and the health service provider. Other explanations can be that individuals in the Booklet group may have read the booklet more intensively than those in the Combined group and therefore, complied more closely with the content, or have used the booklet also later as a guideline.

\section{Methodological considerations}

In our study, about $29 \%$ of the study visits were missing after two years. Multiple imputation attenuated the costeffectiveness results of the Booklet group and the results of the Combined group became less apparent (see Additional file 2). However, the main conclusions of the study remained the same, whether analysed with the imputed or the complete case data (Table 2). The follow-up visit activity was similar in both intervention groups.

CEA showed that results in the Combined group were sensitive to rehabilitation centre inpatient costs. Data show that the cost was due to a single inpatient episode of only one person. If this cost was neglected as an outlier, $\mathrm{HC}$ costs in the Combined would fall at around the same level as in the Booklet group. On the other hand, even though some high cost categories (rehabilitation centre days and hospital inpatient days) were neglected in the $\mathrm{NC}$ group, $\mathrm{HC}$ usage and costs would still remain high in the $\mathrm{NC}$, because $\mathrm{HC}$ usage was higher in almost all $\mathrm{HC}$ categories in comparison with the intervention groups.

Because of the health care perspective in our study, we have omitted non-medical costs such as travel time, time expenses for the $\mathrm{HC}$ visits or out-of-pocket costs. As some previous studies have shown, the impact of these costs would have been minor, anyway.

Our cost data covers the whole study period of two years in the intervention groups. The data show that the 
total direct $\mathrm{HC}$ costs from the whole study period were about twice (data not shown) compared to the costs from the last 12-months' time-sequence in the intervention groups. Therefore, we may estimate that the total 2year costs would be two-fold in the NC group as well. Hence, the incremental cost were estimated as $-392 €$ in the Booklet arm and $-214 €$ in the Combined in two years, negative figure indicating savings.

\section{Comparison with previous studies}

To the best of our knowledge, there are no parallel cost-effectiveness studies that would have randomly allocated mild LBP patients in the groups to whom they have provided information in the $\mathrm{OH}$ setting. Yet, information and advice have already shown to have positive effects on LBP specific outcomes or recovery, either alone $[8,10]$ or as an adjunct to other therapies [33-35] in various other settings.

Previous cost-effectiveness studies in primary care have focused on either acute sciatica [36] or chronic LBP $[37,38]$, i.e. more symptomatic patients [39], than in our study. In the majority of previous studies, patients have also been absent from work [40-42] at baseline. Participants have been recruited either from back clinics or other physician consultations, or invited to participate in the study on the basis of SA records. Primary care interventions for sub-acute or recurrent LBP have been cost-effective in many cases [43]. However, the usual care control group has not been consistent or properly defined in these studies. In addition, these interventions have generally been carried out by a physician or in collaboration with a physiotherapist and therefore, are not entirely comparable with our study.

In our previous RCT, we found no difference in the health-related outcomes between the two mild LBP patient information arms [15]. However, when compared with the natural course of LBP we found a consistent reduction in PHI and also $\mathrm{HC}$ costs in both patient information arms.

Some recent studies have shown that a LBP management strategy that is based on a patient-level riskassessment (e.g. low, medium or high risk of LBP) in primary care is more efficient and cost-effective than a non-stratified approach [44-46]. Hill et al. [46] found that the interventions (patient information and physiotherapist consultations) were cost-effective for mediumand high-risk patients. The low-risk subgroup only received one patient information session (educational video and the Back Book). As a result, work loss decreased in the low risk intervention group in comparison to the control group (usual care). Although their recruitment strategy was different from ours, the main characteristics of the study participants in the low-risk group are comparable. Whitehurst et al. later analysed the results of the low-risk group [44] and found that the intervention was cost effective also in the low-risk subgroup.

\section{Clinical significance of the study}

Due to our focus on mild LBP, PHI values were relatively low at baseline. Nevertheless, we discovered a small, yet significant, mean difference in the group comparisons against natural course of LBP. Although the effect sizes were modest in absolute figures, the proportional effects in both comparisons were 36-60\% of the corresponding baseline values. The results were also long-lasting [47]. RolandMorris Disability Questionnaire is rather insensitive to change when symptom levels are low [48], suggesting that even minor differences may be of importance.

The study participants were recruited and the interventions were carried out in a pragmatic $\mathrm{OH}$ environment by an $\mathrm{OH}$ nurse. Our results indicate that the $\mathrm{OH}$ system can reconsider their professional roles and errands. In contrast to previous physician-led interventions, our nurse-guided patient information was cost-effective in mild LBP, and there was no need for the support of a physiotherapist or a physician. In the case of mild LBP, health examinations in the $\mathrm{OH}$ could be more targeted and perform a stratified, symptom-based, preventive approach. Our results indicate that a proactive, targeted LBP management with appropriate patient information leads to positive outcomes and reduced costs in the $\mathrm{OH}$ setting [49].

According to the health care usage (see Additional file 1), a vast majority of all primary care consultations (mainly by nurses and physicians) were performed at the $\mathrm{OH}$ service. Until present, $\mathrm{OH}$ service plays an important role in the primary health care of the Finnish working population. It also has resources and ability to bring secondary preventive actions into practice [50].

For the employees that reported mild LBP, simple patient information booklet was effective and cost-saving in comparison with the natural course of LBP. Further studies in this field should aim at larger patient samples, and introduce a genuine randomised design also concerning the control group.

\section{Conclusions}

Low back specific patient information booklet was costeffective in comparison with the natural course of LBP over two years. Booklet intervention with additional face-to-face information resulted in lower health care costs, but the effectiveness in sickness absence was minimal. Physical impairment decreased in both intervention arms. Simple booklet information is beneficial for employees who report mild LBP in the $\mathrm{OH}$ setting, and also saves costs of the health care system. 


\section{Study ethics}

The South Karelian Central Hospital Research Ethics Board approved the study on 13.09.2001. All participants received written information regarding the study, in accordance with the Declaration of Helsinki. Only the participants who gave their signed informed consent were included in the study. The documents above are stored with the other study material.

\section{Additional files}

Additional file 1: Health care $(\mathrm{HC})$ resource usage and direct $\mathrm{HC}$ costs in all study groups (with the number of participants indicated) during the last 12 months of the two-year follow-up according to available data (data not imputed). Number of units per group, unit cost, total cost per group and mean cost (per participant) with standard deviation (SD). Subtotals show units and costs in some basic HC categories. Zero unit/ cost lines have been deleted. [HC, health care; $\mathrm{OH}$, Occupational health; Booklet, Back Book group; Combined, Back Book and advice group; NC, Natural course group; PT, physiotherapist; OPR, other professional]. (DOCX 209 kb)

Additional file 2: The results of two cost-effectiveness analyses (CEA), based on the multiply imputed data (main analysis) and the complete case analysis (original data). Table also shows the mean monetary savings per person in the group comparisons of the intervention groups (Combined and Booklet) against the control (NC=natural course of LBP group) as well as the distribution of bootstrapped, simulated cases across the CE plane qvadrants (in percentages). [mean; 95\% Cl = $95 \%$ confidence interval; ICER = incremental cost-effectiveness ratio; incremental costs and effects]. (DOCX 202 kb)

Additional file 3: Cost-effectiveness acceptability curves (CEAC) of the comparisons Booklet vs. NC (dotted line) and Combined vs. NC (solid line). CEAC line indicates the probability that the intervention is costeffective in comparison to NC (natural course of mild LBP) when the maximum acceptable cost per SA day is $200 €$ [Booklet, Back Book booklet group; Combined, Back Book with oral advice group; CEA, cost-effectiveness analysis]. (DOCX $49 \mathrm{~kb}$ )

\section{Abbreviations}

Booklet: booklet alone patient information arm; CE: cost-effectiveness; CEA: cost-effectiveness analysis; CEAC: cost-effectiveness acceptability curve; Combined: booklet and verbal advice patient information arm; $\mathrm{HC}$ : health care; IC: incremental cost; ICER: inceremental cost-effectiveness ratio; IE: incremental effect; LB: Iow back; LBP: low back pain; NC: natural course control group; PHI: physical impairment; SA: sickness absence days; SD: standard deviation.

\section{Competing interests}

The authors declare that they have no competing interests.

\section{Authors' contributions}

$J R$ was involved in the study planning, organised and managed the interventions, calculated the basic statistics and wrote the outline of the manuscript. AV contributed the advanced statistics, and SL was involved in the data management. JK, AM, ST, and MH participated in the planning of the study. ST and JK interpreted the results at every phase of the project. EVJ and all the other authors critically revised the manuscript and made suggestions during the writing process. All authors read and approved the final manuscript.

\section{Acknowledgements}

The Finnish Work Environment Fund funded this study (grant number 114047/ Dr Jarmo Rantonen). The author's work is independent of the funder.

\section{Author details}

${ }^{1}$ Finnish Institute of Occupational Health (FIOH), P.B. 4000251 Helsinki, Finland. ${ }^{2}$ Helsinki Institute for Information Technology HIIT, Department of Computer Science, Aalto University, Espoo, Finland. ${ }^{3}$ Department of Physical Medicine and Rehabilitation, South Karelia Social and Health Care District, Lappeenranta, Finland. ${ }^{4}$ Medical Research Center Oulu, University of Oulu and Oulu University Hospital, Oulu, Finland. ${ }^{5}$ National Institute for Health and Welfare, Centre for Health and Social Economics, Helsinki, Finland. ${ }^{6}$ Evalua International, Espoo, Finland. ${ }^{7}$ Hjelt Institute, Department of Public Health, University of Helsinki, Helsinki, Finland. ${ }^{8}$ South Karelian Institute, Lappeenranta University of Technology, Lappeenranta, Finland. ${ }^{9}$ University of Helsinki, Helsinki, Finland.

Received: 9 December 2015 Accepted: 21 March 2016

Published online: 12 April 2016

\section{References}

1. Hoy D, Brooks P, Blyth F, Buchbinder R. The Epidemiology of low back pain. Best Pract Res Clin Rheumatol. 2010;24(6):769-81.

2. Hoy D, March L, Brooks P, Woolf A, Blyth F, Vos T, Buchbinder R. Measuring the global burden of low back pain. Best Pract Res Clin Rheumatol. 2010; 24(2):155-65

3. Koes BW, van Tulder M, Lin CW, Macedo LG, McAuley J, Maher C. An updated overview of clinical guidelines for the management of non-specific low back pain in primary care. Eur Spine J. 2010;19(12):2075-94.

4. Burton AK, Balague F, Cardon G, Eriksen HR, Henrotin Y, Lahad A, Leclerc A, Muller G, van der, Beek AJ. Chapter 2. European guidelines for prevention in low back pain : November 2004. Eur Spine J. 2006;15 Suppl 2:S136-68.

5. Driscoll T, Jacklyn G, Orchard J, Passmore E, Vos T, Freedman G, et al. The global burden of occupationally related low back pain: estimates from the Global Burden of Disease 2010 study. Ann Rheum Dis. 2014;73(6):975-81.

6. Pellise F, Sell P. Patient information and education with modern media: the Spine Society of Europe Patient Line. Eur Spine J. 2009;18 Suppl 3:395-401.

7. Burton AK, Waddell G, Burtt R, Blair S. Patient educational material in the management of low back pain in primary care. Bull Hosp Jt Dis. 1996; 55(3):138-41.

8. Burton AK, Waddell G, Tillotson KM, Summerton N. Information and advice to patients with back pain can have a positive effect. A randomized controlled trial of a novel educational booklet in primary care. Spine. 1999;24(23):2484-91.

9. Laher M, O'Malley K, O'Brien E, O'Hanrahan M, O'Boyle C. Educational value of printed information for patients with hypertension. Br Med J. 1981; 282(6273):1360-1.

10. Roberts L, Little P, Chapman J, Cantrell T, Pickering R, Langridge J. The back home trial: general practitioner-supported leaflets may change back pain behavior. Spine. 2002;27(17):1821-8.

11. Coulter A. Evidence based patient information. BMJ. 1998;317(7153):225-6.

12. Frost $P$, Haahr JP, Andersen JH. Reduction of pain-related disability in working populations: a randomized intervention study of the effects of an educational booklet addressing psychosocial risk factors and screening workplaces for physical health hazards. Spine. 2007;32(18):1949-54.

13. Coudeyre E, Tubach F, Rannou F, Baron G, Coriat F, Brin S, Revel M, Poiraudeau S. Effect of a simple information booklet on pain persistence after an acute episode of low back pain: a non-randomized trial in a primary care setting. PLOS ONE. 2007;2(1):e706.

14. Engers $A$, Jellema $P$, Wensing $M$, van der Windt DA, Grol R, van Tulder MW. Individual patient education for low back pain. Cochrane Database Syst Rev. 2010;1:CD004057.

15. Rantonen J, Vehtari A, Karppinen J, Luoto S, Viikari-Juntura E, Hupli M, Malmivaara A, Taimela S. Face-to-face information combined with a booklet versus a booklet alone for treatment of mild low-back pain: a randomized controlled trial. Scand J Work Environ Health. 2014;40(2):156-66.

16. Brox II, Storheim K, Grotle M, Tveito TH, Indahl A, Eriksen HR. Systematic review of back schools, brief education, and fear-avoidance training for chronic low back pain. Spine J. 2008;8(6):948-58.

17. Udermann BE, Spratt KF, Donelson RG, Mayer J, Graves JE, Tillotson J. Can a patient educational book change behavior and reduce pain in chronic low back pain patients? Spine J. 2004;4(4):425-35.

18. Albaladejo C, Kovacs FM, Royuela A, del Pino R, Zamora J. The efficacy of a short education program and a short physiotherapy program for treating low back pain in primary care: a cluster randomized trial. Spine (Phila Pa 1976). 2010;35(5):483-96 
19. The Statistical Yearbook of the Social Insurance Institution. In: Official Statistics of Finland. The Social Insurance Institution of Finland; 2013. p. 465.

20. Rasanen K, Husman K. National follow-up of occupational health services system in Finland. Appl Occup Environ Hyg. 2003;18(6):413-5.

21. Rasanen K, Notkola V, Kankaanpaa E, Peurala M, Husman K. Role of the occupational health services as a part of illness-related primary care in Finland. Occup Med (Lond). 1993;43 Suppl 1:S23-7.

22. Kimanen A, Rautio M, Manninen P, Rasanen K, Husman P, Husman K. Primary care visits to occupational health physicians and nurses in Finland. Scand J Public Health. 2011;39(5):525-32.

23. Rantonen J, Luoto S, Vehtari A, Hupli M, Karppinen J, Malmivaara A, Taimela S The effectiveness of two active interventions compared to self-care advice in employees with non-acute low back symptoms: a randomised, controlled trial with a 4-year follow-up in the occupational health setting. Occup Environ Med. 2012;69(1):12-20.

24. Boonstra AM, Schiphorst Preuper HR, Balk GA, Stewart RE. Cut-off points for mild, moderate, and severe pain on the visual analogue scale for pain in patients with chronic musculoskeletal pain. Pain. 2014;155(12):2545-50.

25. Hujanen T, Kapiainen S, Tuominen U, Pekurinen M. Terveydenhuollon yksikkökustannukset Suomessa vuonna 2006 (Healthcare unit costs in Finland in year 2006). Helsinki: Stakes; 2008.

26. Roland M, Morris R. A study of the natural history of back pain. Part I: development of a reliable and sensitive measure of disability in low-back pain. Spine. 1983;8(2):141-4.

27. Stratford PW, Binkley JM. Measurement properties of the RM-18. A modified version of the Roland- Morris Disability Scale. Spine. 1997;22(20):2416-21.

28. Million R, Hall W, Nilsen KH, Baker RD, Jayson Ml. Assessment of the progress of the back-pain patient 1981 Volvo Award in Clinical Science. Spine. 1982;7(3):204-12.

29. WHO. International Statistical Classification of Diseases and Related Health Problems (ICD-10). In: 10th revision. Geneva: World Health Organization; 2003.

30. Burton A, Billingham $L$, Bryan S. Cost-effectiveness in clinical trials: using multiple imputation to deal with incomplete cost data. Clin Trials. 2007;4(2): 154-61

31. Kivimaki M, Head J, Ferrie JE, Shipley MJ, Vahtera J, Marmot MG. Sickness absence as a global measure of health: evidence from mortality in the Whitehall II prospective cohort study. BMJ. 2003;327(7411):364.

32. Marmot M, Feeney A, Shipley M, North F, Syme SL. Sickness absence as a measure of health status and functioning: from the UK Whitehall II study. J Epidemiol Community Health. 1995:49(2):124-30.

33. Henrotin YE, Cedraschi C, Duplan B, Bazin T, Duquesnoy B. Information and low back pain management: a systematic review. Spine (Phila Pa 1976). 2006;31(11):e326-34

34. Cherkin DC, Deyo RA, Battie M, Street J, Barlow W. A comparison of physical therapy, chiropractic manipulation, and provision of an educational booklet for the treatment of patients with low back pain. N Engl J Med. 1998; 339(15):1021-9.

35. Whitfill T, Haggard R, Bierner SM, Pransky G, Hassett RG, Gatchel RJ. Early intervention options for acute low back pain patients: a randomized clinical trial with one-year follow-up outcomes. J Occup Rehabil. 2010;20(2):256-63.

36. Luijsterburg PA, Verhagen AP, Ostelo RW, van den Hoogen HJ, Peul WC, Avezaat CJ, Koes BW. Physical therapy plus general practitioners' care versus general practitioners' care alone for sciatica: a randomised clinical trial with a 12-month follow-up. Eur Spine J. 2008;17(4):509-17.

37. Becker A, Held H, Redaelli M, Strauch K, Chenot JF, Leonhardt C, Keller S, Baum E, Pfingsten M, Hildebrandt J et al. Low back pain in primary care: costs of care and prediction of future health care utilization. Spine (Phila Pa 1976). 2010;35(18):1714-20.

38. Lamb SE, Hansen Z, Lall R, Castelnuovo E, Withers EJ, Nichols V, Potter R Underwood MR. Group cognitive behavioural treatment for low-back pain in primary care: a randomised controlled trial and cost-effectiveness analysis. Lancet. 2010;375(9718):916-23.

39. Jellema $P$, van der Roer $N$, van der Windt DA, van Tulder MW, van der Horst HE, Stalman WA, Bouter LM. Low back pain in general practice: costeffectiveness of a minimal psychosocial intervention versus usual care. Eur Spine J. 2007;16(11):1812-21

40. Steenstra IA, Anema JR, van Tulder MW, Bongers PM, de Vet HC, van Mechelen W. Economic evaluation of a multi-stage return to work program for workers on sick-leave due to low back pain. J Occup Rehabil. 2006;16(4):557-78.
41. Lambeek LC, Bosmans JE, Van Royen BJ, Van Tulder MW, Van Mechelen W, Anema JR. Effect of integrated care for sick listed patients with chronic low back pain: economic evaluation alongside a randomised controlled trial. BMJ. 2010;341.

42. Jensen C, Nielsen CV, Jensen OK, Petersen KD. Cost-effectiveness and costbenefit analyses of a multidisciplinary intervention compared with a brief intervention to facilitate return to work in sick-listed patients with low back pain. Spine (Phila Pa 1976). 2013;38(13):1059-67.

43. Lin CW, Haas M, Maher CG, Machado LA, van Tulder MW. Cost-effectiveness of guideline-endorsed treatments for low back pain: a systematic review. Eur Spine J. 2011;20(7):1024-38.

44. Whitehurst DG, Bryan S, Lewis M, Hill J, Hay EM. Exploring the cost-utility of stratified primary care management for low back pain compared with current best practice within risk-defined subgroups. Ann Rheum Dis. 2012; 71(11):1796-802

45. Hill JC, Dunn KM, Lewis M, Mullis R, Main CJ, Foster NE, Hay EM. A primary care back pain screening tool: identifying patient subgroups for initial treatment. Arthritis Rheum. 2008;59(5):632-41.

46. Hill JC, Whitehurst DGT, Lewis M, Bryan S, Dunn KM, Foster NE, Konstantinou K, Main CJ, Mason E, Somerville S et al. Comparison of stratified primary care management for low back pain with current best practice (STarT Back): a randomised controlled trial. Lancet. 2011:378(9802):1560-71.

47. Artus M, van der Windt D, Jordan KP, Croft PR. The clinical course of low back pain: a meta-analysis comparing outcomes in randomised clinical trials (RCTs) and observational studies. BMC Musculoskelet Disord. 2014;15:68.

48. Hall AM, Maher CG, Latimer J, Ferreira ML, Costa LO. The patient-specific functional scale is more responsive than the Roland Morris disability questionnaire when activity limitation is low. Eur Spine J. 2011;20(1):79-86.

49. Dupeyron A, Ribinik P, Gélis A, Genty M, Claus D, Hérisson C, Coudeyre E. Education in the management of low back pain. Literature review and recall of key recom. Ann Phys Rehabil Med. 2011;54(5):319-35.

50. Taimela S, Justen S, Aronen P, Sintonen H, Laara E, Malmivaara A, Tiekso J, Aro T. An occupational health intervention programme for workers at high risk for sickness absence. Cost effectiveness analysis based on a randomised controlled trial. Occup Environ Med. 2008;65(4):242-8.

\section{Submit your next manuscript to BioMed Central and we will help you at every step:}

- We accept pre-submission inquiries

- Our selector tool helps you to find the most relevant journal

- We provide round the clock customer support

- Convenient online submission

- Thorough peer review

- Inclusion in PubMed and all major indexing services

- Maximum visibility for your research

Submit your manuscript at www.biomedcentral.com/submit
BioMed Central 